\title{
Using satellite altimetry and tide gauges for storm surge warning
}

\author{
OLE B. ANDERSEN ${ }^{1}$, Y. CHENG ${ }^{1}$, X. DENG ${ }^{2}$, M. STEWARD ${ }^{2} \&$ \\ Z. GHARINEIAT ${ }^{2}$ \\ 1 DTU Space, Elektrovej, Lyngby, Denmark \\ oa@space.dtu.dk \\ 2 The University of Newcastle, Callaghan, NSW, Australia
}

\begin{abstract}
The combination of the coarse temporal sampling by satellite altimeters in the deep ocean with the high temporal sampling at sparsely located tide gauges along the coast has been used to improve the forecast of high water for the North Sea along the Danish Coast and for the northeast coast of Australia. For both locations we have tried to investigate the possibilities and limitations of the use of satellite altimetry to capture high frequency signals (surges) using data from the past 20 years. The two regions are chosen to represent extra-tropical and tropical storm surge conditions. We have selected several representative high water events on the two continents based on tide gauge recordings and investigated the capability of satellite altimetry to capture these events in the sea surface height data. Due to the lack of recent surges in the North Sea we focused on general high water level and found that in the presence of two or more satellites we could capture more than $90 \%$ of the high water sea level events. In the Great Barrier Reef section of the northeast Australian coast, we have investigated several large tropical cyclones; one of these being Cyclone Larry, which hit the Queensland coast in March 2006 and caused both loss of lives as well as huge devastation. Here we demonstrate the importance of integrating tide gauges with satellite altimetry for forecasting high water at the city of Townsville in northeast Australia.
\end{abstract}

Key words satellite altimetry; sea level; storm surges.

\section{INTRODUCTION}

Tide gauges and satellite altimetry have vastly different spatial and temporal sampling. Radar altimeters on board satellites measure sea level from a height of $1000 \mathrm{~km}$, as well as wind speed and wave height over a 2 to $5 \mathrm{~km}$ radius. The observations are measured in a global mesh with observations taken along the ground tracks every $6 \mathrm{~km}$ and with a typical distance between the ground-tracks of 100-300 km. The observations are typically repeated every 10 to 35 days. Tide gauges are fundamentally different to satellites as they measure sea level typically every second or minute but only at sparse coastal locations.

The two data types can be integrated to take advantage of the high temporal sampling of the tide gauges with the high spatial sampling of the satellite. Combining the data we have tried to investigate and detect storm-induced high water signals in the two fundamentally different coastal regions prone to storm surges. One is the west coast of Denmark in the North Sea, and the other the Great Barrier Reef region of northeast Australia. We have used data for the past 20 years to investigate the ability of satellite altimetry to capture storm induced high water events hours to days in advance away from the coast.

Exceptionally high sea level has claimed many victims throughout the history of both Australia and the countries around the North Sea (Gill, 1982). The sea level variability in both the North Sea and Great Barrier Reef is dominated by ocean tides. In the case of the North Sea it has a range of up to $4 \mathrm{~m}$ at some locations along the east coast of England (Flather, 2000). The most important non-tidal contribution to sea level variations is weather induced surges which can act together with the tidal variations and cause flooding of the low lying regions on the coast. Tropical storm surges as seen in Australia are different in nature to extra-tropical storm surges seen at midlatitudes (Von Storch and Wort, 2008). Tropical storm surges are much less frequent at a given position than at mid-latitudes; they are also considerably more limited in extent (200-500 km vs 500-1000 km, respectively; Gönnert et al., 2001). But if they hit, then the effect is usually stronger than in mid-latitudes. Both tropical and extra-tropical storm surges are by nature much more difficult to predict than the tidal variations due to the dependence on the performance of weather forecasts (Heaps, 1967, 1983). 
Modern satellite altimeters like the Jason satellites have an accuracy that enables them to detect surges through observations of wind speed; wave height and sea surface height. The sea surface height is an important parameter, as it is a proxy in the tropical regions for the vertically integrated heat content within the water column which provides the reservoir of energy available to intensify a tropical storm (Shay et al., 2000).

We have investigated a tropical storm that hit northeastern Australia in 2006 named Cyclone Larry. This cyclone was not only very fierce but also limited in spatial extent which makes it a challenge to capture from satellite altimetry. This investigation illustrates that it is possible to capture the cyclone in sea level as well as the other parameters, but also that including the observations in a multi-regression model of the region leads to significantly improved sea level forecasting at the tide gauge in Cape Ferguson (Townsville).

\section{CAPTURING HIGHWATER IN THE NORTH SEA FROM SATELLITE ALTIMETRY}

The North Sea is a marginal sea to the Northeast Atlantic Ocean and surges normally propagate in a westerly direction from north of Britain and down through the North Sea until they hit the coast of Denmark. Figure 1 illustrates the location of the Hvidesande tide gauge recorder on the west coast of Denmark and the temporal variation of sea level at the gauge. We have computed the normal variation of sea level by computing the standard deviation of the observed sea level - this is $49 \mathrm{~cm}$ including the tides -then we marked all episodes when the sea level was higher than twice the standard deviation with green in Fig. 1. Besides these episodes, there are five episodes of sea level higher than three times the standard deviation of normal variations. These are marked with arrows.

The altimetric observations used here are taken from the Radar Altimetry Data System (RADS) in a special version where the satellite data has maintained the inverse barometer effects due to changes in sea level pressure in order not to remove part of the surge signal from the altimetric data. This is also to be consistent with the water level recorders where the effects are also present. We have used available satellite altimetry data for the 1997-2001 period including the TOPEX/POSEIDON and ERS-2 satellites.

The satellite ground tracks are shown in the insert in Fig. 2. Here the blue tracks illustrate the TOPEX/POSEIDON ground tracks and the red tracks illustrate the ERS-2 tracks. For each location along the satellite's ground track the four years of data were used to compute the standard deviation. This can be considered to represent normal conditions. Again we pick the instances where the altimeter-derived sea surface height is higher than two times the standard deviation. First we pick the data in the small black box from TOPEX/POSEIDON and mark the instances of high water observed by the satellite altimeter. This is illustrated using the red line in Fig. 2. It can be seen that this roughly captures half of the high water instances found by the tide gauge at Hvidesande. It is also visible that it captures three out of five of the instances of 3 times the standard deviation marked with arrows in Fig. 1.

The work by Høyer and Andersen (2003) showed that the surges to a large degree propagate in a counter-clock wise rotation around the North Sea because it is so shallow. This causes a delay between Aberdeen in Scotland in the northwest North Sea, and Hvidesande in the southeast, of roughly 12 hours. Figure 3 shows the temporal correlation between the tide gauge readings at Aberdeen and Hvidesande. We can take advantage of this counter-clock wise rotation and extend the black box in Fig. 2 towards the west to capture the surge earlier as it propagates across the North Sea. This extended box is shown in red. High water events captured by altimetry from tracks in this box are illustrated using purple in Fig. 2. Several more instances are captured, but also a few that do not lead to high water in Hvidesande can be seen. However, the TOPEX/POSEIDON satellite still only captures three out of the five instances of 3 times the standard deviation corresponding to $1.5 \mathrm{~m}$ above normal water level. The reason for this stems from the fact that the surge propagates across the North Sea within roughly 12 hours. The TOPEX/POSEIDON repeats its observations every ten days, but it only has six tracks within the red box. Consequently we have an observation from the TOPEX/POSEIDON satellite roughly every 1.5 days which is slightly too infrequent to capture all surges or high water events. 


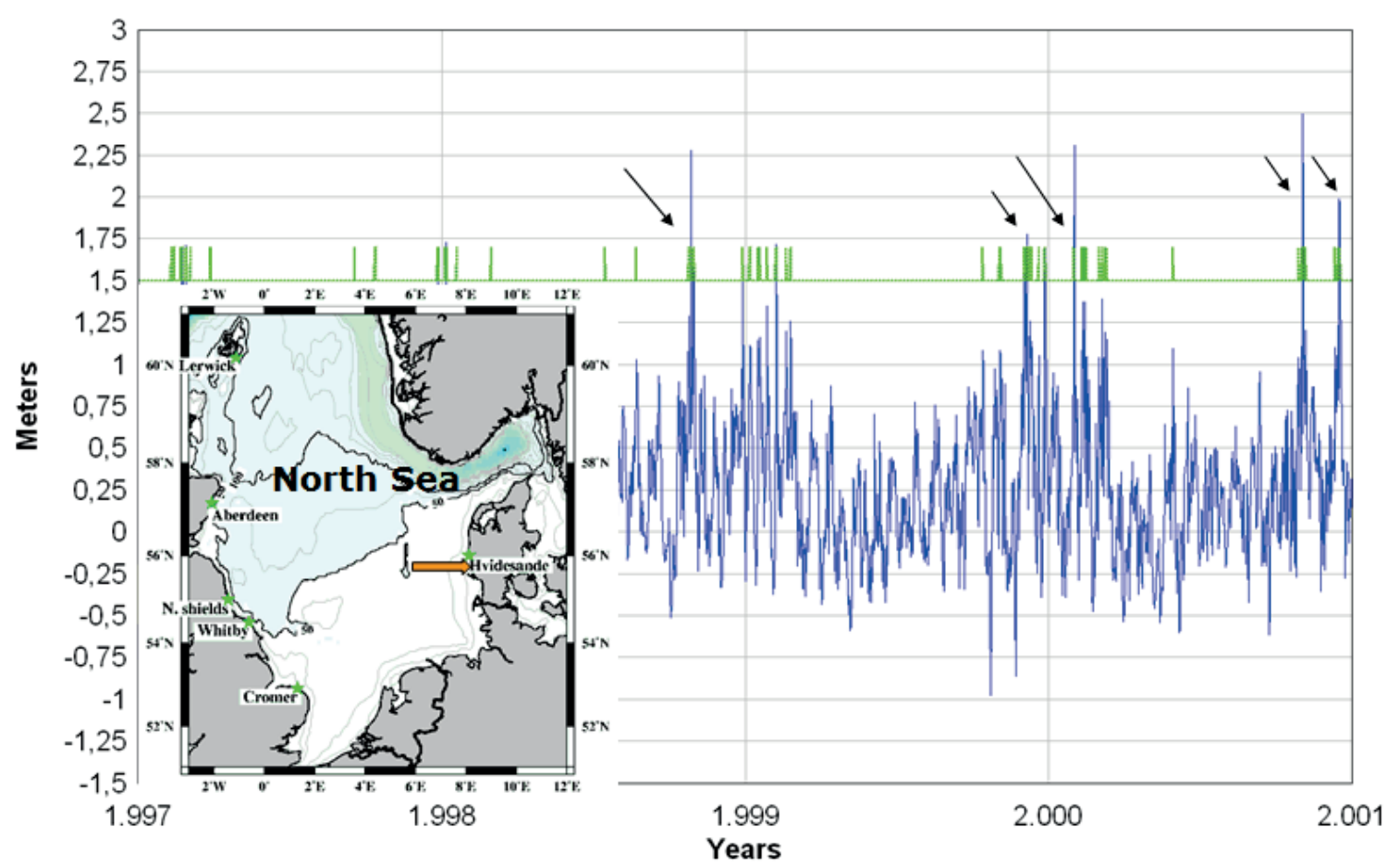

Fig. 1 The location of the Hvidesande tide gauge recorder on the west coast of Denmark and the sea level variations (including tides) recorded by the gauge for the 1997-2001 period (blue). Episodes when sea level was higher than 2 times the standard deviation are marked with green, and 5 episodes of sea level higher than 3 times the standard deviation are marked with arrows. All heights are given in metres.

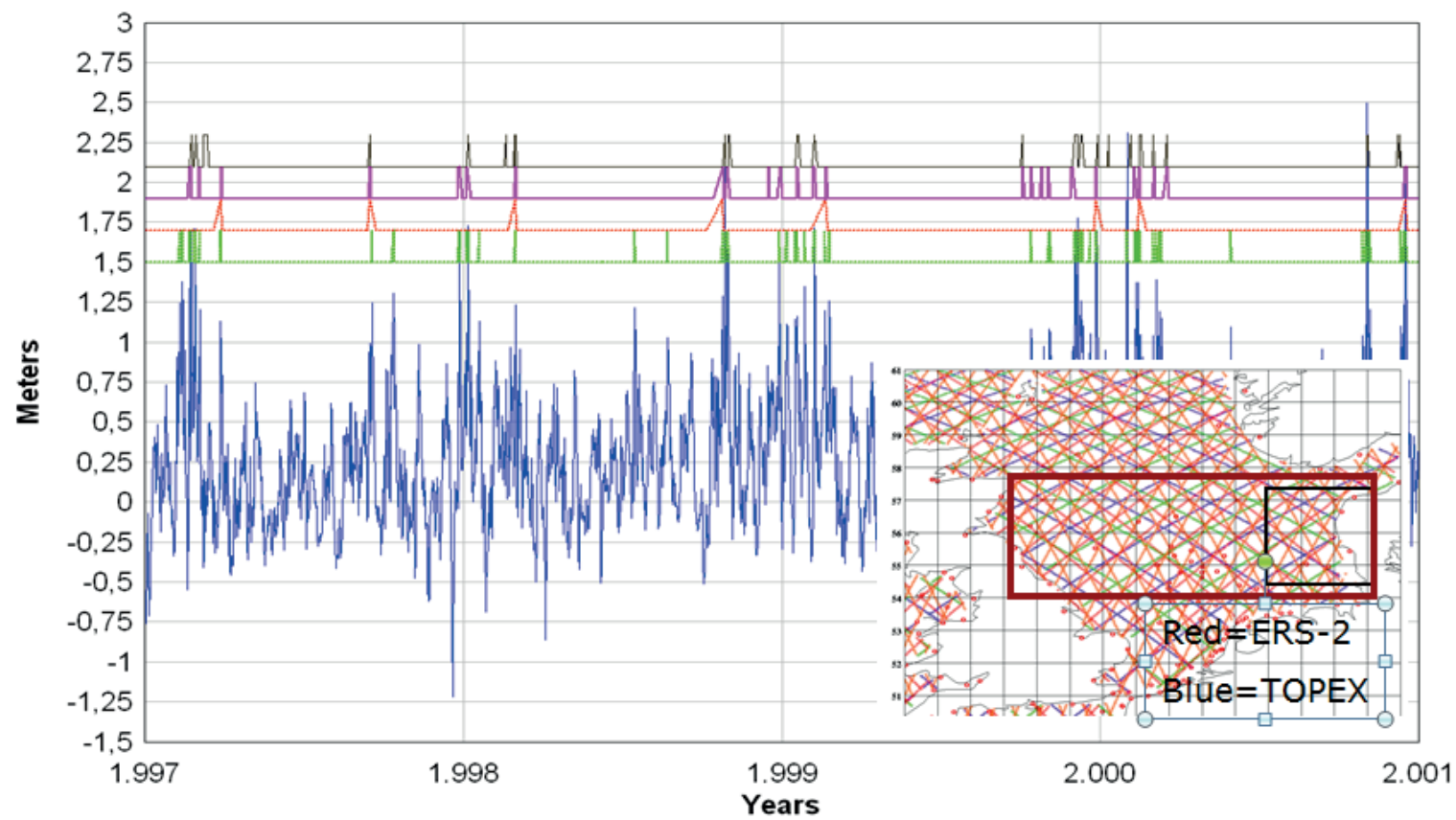

Fig. 2 Tide gauge recordings (in blue) at Hvidesande for the 1997-2001 period in metres. The inserted picture shows altimetry tracks in the North Sea from TOPEX/POSEIDON and ERS-1/2. Episodes when the sea level at the Hvidesande tide-gauge was higher than 2 times the standard deviation are marked in green. High water events captured by the TOPEX/POSEIDON satellite within the black box are marked in red. High water events captured by the TOPEX/POSEIDON satellite within the red box, are marked with purple. High waver events recorded by the ERS-2 satellite within the red box are marked with black. 


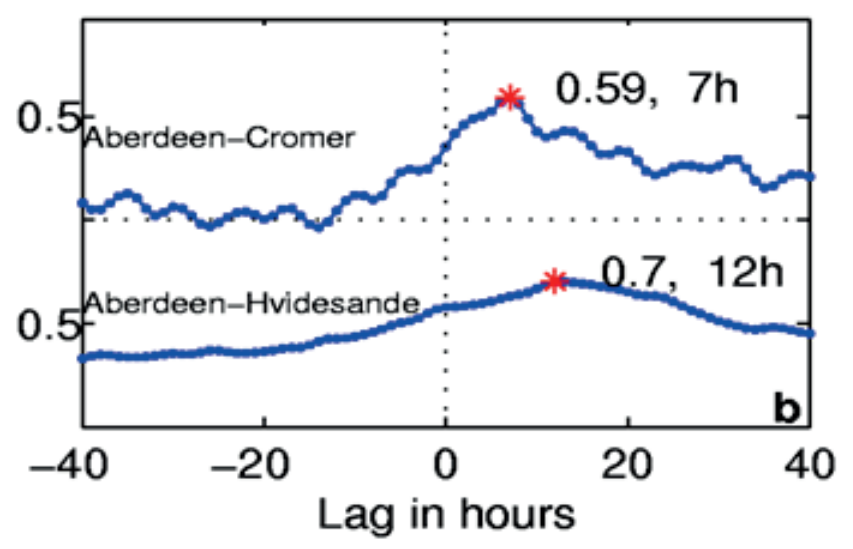

Fig. 3 Cross-correlation between the tide gauge level in Aberdeen and the tide gauge level in Cromer on the central east coast of Britain and the tide gauge in Hvidesande, Denmark (scale 0-1). See Fig. 1 for locations. There is a clear 7 hour time delay between Aberdeen in Scotland in the northwest part of the North Sea and the Cromer tide gauge in the southwest part of the North Sea. The maximum crosscorrelation between Aberdeen and Hvidesande is found after 12 hours, corresponding to a 12 hour propagation time of the surge between Aberdeen in the northwest part and Hvidesande in the southeast part of the North Sea.

Therefore it is important to include an additional satellite in the investigation to capture the remaining high water events. The result using the ERS-2 satellite is shown with black in Fig. 2. It can be seen that all episodes of high water higher than 3 times the standard deviation are now captured. This illustrates the fundamental importance of having more than one satellite for capturing surges in the North Sea due to the speed and nature of the extra-tropical surges.

In the following investigation we have tried to investigate the ability of satellite altimetry in capturing tropical cyclones in the northeast of Australia. Whereas the North Sea is a marginal sea to the North Atlantic, the northeast Australian coast faces the Pacific Ocean directly. This means that the propagation of the related surge will not be affected to the same degree as in the North Sea but more directly follows the path of the low pressure system.

\section{TROPICAL CYCLONE LARRY}

In order to illustrate the ability of satellite altimetry to capture tropical cyclones we studied several cyclones. Here we decided to focus on just one. The tropical cyclone Larry made landfall at the tropical Queensland coast near Innisfail on Monday 20 March 2006. Figure 4 shows the track of Larry (top left panel), a photo-like image of Larry acquired by the Moderate Resolution Imaging Spectro-radiometer (MODIS) on NASA's Aqua satellite with an overlapping altimetry pass (Jason-1, pass 149 of cycle 154) on 19 March 2006 (top right panel). The tropical cyclone low developed over the eastern Coral Sea and reached cyclone intensity during the early hours of 18 March and continued on a general westerly course towards the Queensland coast. Larry rapidly strengthened in the following 48 hours reaching hurricane-force intensity at 12:00 UTC 18 March and peaking at $56 \mathrm{~m} / \mathrm{s}$ (110 knots) at 12:00 UTC 19 March as it marched gradually westwards towards the coast, as also illustrated in Fig. 4. The along-track altimetric sea level anomalies are shown in green, along with the two times the "normal" standard deviations (in blue) in the lower panel. Solid blue dots marks the mean of sea level anomalies for the 2005-2007 period and due to the El Nino effect this is different to zero represented by the DTU10 mean sea surface (Andersen $\&$ Knudsen, 2009). The sea level anomalies when the satellite crossed the cyclone near longitude $158^{\circ} \mathrm{E}$ are shown.

Figure 5 illustrates the data available from RADS and preprocessed by the international space centres. Altimetric tracks within 12 hours and $500 \mathrm{~km}$ of tropical cyclone Larry are shown. The figure shows all three parameters derived from satellite altimetry: the sea surface height (left), wind speed (centre) and significant wave height (right). The cyclone is easily seen in all quantities. However, it is obvious that a lot of the data right in the centre of the storm are missing. This is 


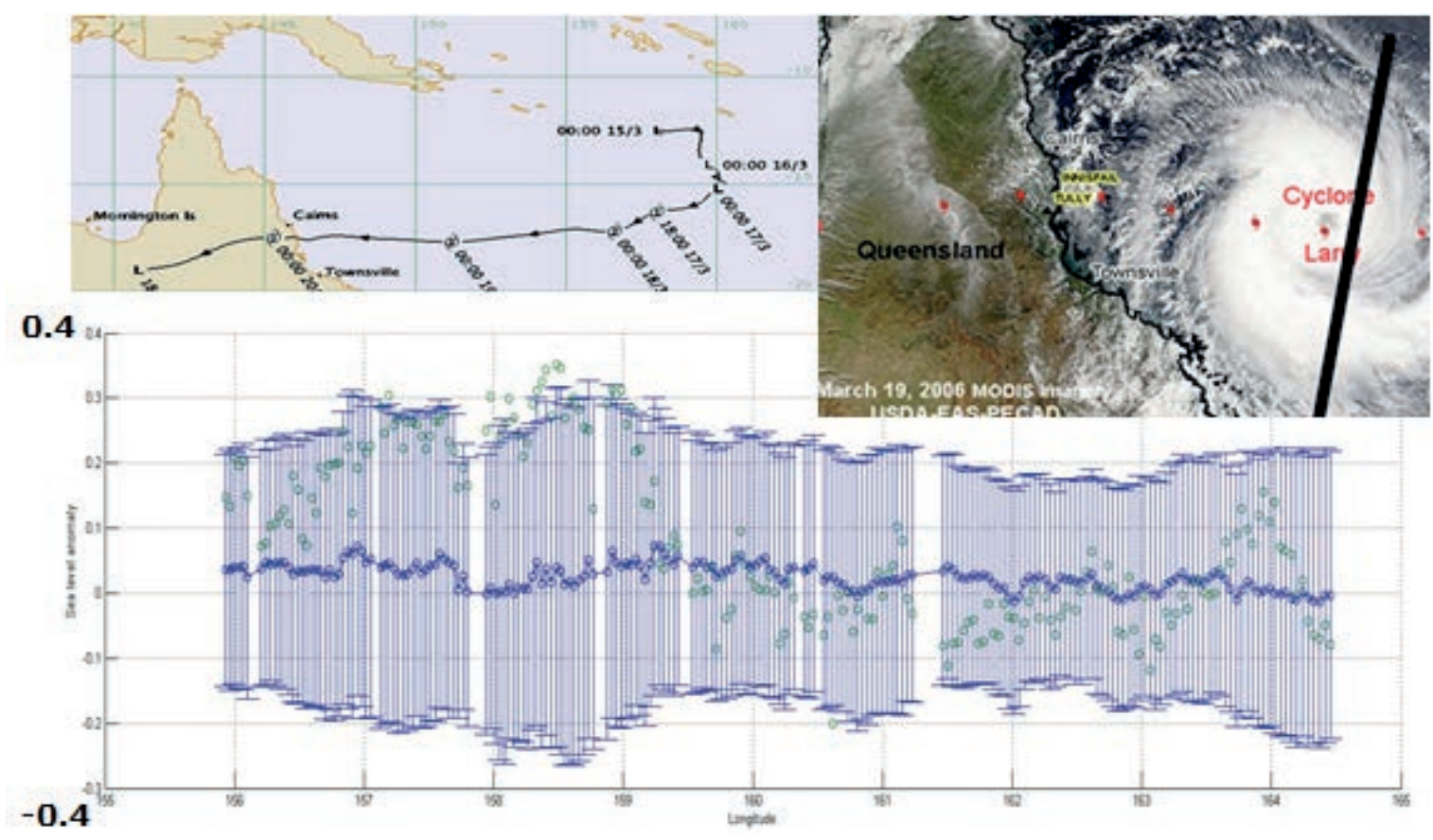

Fig. 4 The tropical cyclone Larry that hit the Queensland coast in March 2006. The upper left figure shows the path, category of Larry and the dates of the cyclone. The upper right picture is a MODIS image from 19 March 2006 with the Jason-2 track. The lower left picture shows the retracked sea surface height along the track shown in Fig. 5. The mean sea level anomalies (SLAs) around zero are shown in solid blue circles. The 2 times standard deviations are shown in blue bars. The observed SLAs during the cyclone Larry are shown in green circles (values are given in meters).

mainly caused by the heavy rain associated with the cyclone. This makes the satellite recording of power vs time (waveform) not look like a standard Brown waveform, and hence it is fails to retrack and is rejected as a bad observation. However, the waveform can be recovered and we retracked it using the Deng et al. (2012) waveform retracking system. The result of this retracking is shown in the lower left part of Fig. 4. The section shown in Fig. 4 corresponds to the track in Fig. 5. The blue dots and lines mark the mean and two times the standard deviation of the sea surface height, and the green marks the observed sea surface height by the satellite the day Larry crossed the track. The high sea surface height associated with the cyclone Larry is clearly seen. However, it only stands out marginally from two times normal sea surface variability. This is because non-tidal variability within this section of the Pacific is very large with frequent storms. Furthermore, the region is strongly influenced by the El Nino-La Nina signal in sea level.

The retracked altimeter observations for an extended period around the cyclone Larry have been used to perform a multi-regression model (Høyer \& Andersen, 2003; Cheng \& Andersen, 2012; Deng et al., 2012) along with the data from six tide gauges seen in Fig. 6. The Cape Ferguson tide gauge near Townsville has not been used as we want to estimate sea surface height for Townsville where cyclone Larry made landfall. We subsequently compared the sea level predicted from either tide gauges alone or from tide gauges and satellite altimetry with the recorded sea level at the Cape Ferguson tide gauge.

Figure 6 also illustrates the performance of the multi-regression model on predicting sea level. The upper figure coded in colours illustrates the spatial distribution of hindcast skills, which presents the proportion of the sea level observed by altimetry that is explained by tide gauges through the multivariate regression model. It is seen that the hindcast skill is close to 1 while near to the various gauges and also high throughout the Gulf of Carpentaria, whereas it is close to zero away from the eastern coast of Australia. This illustrates that the tide gauges are representing sea level variations close and, in some cases, also far from the coast. In this investigation the tide gauge at Cape Ferguson was also included. 


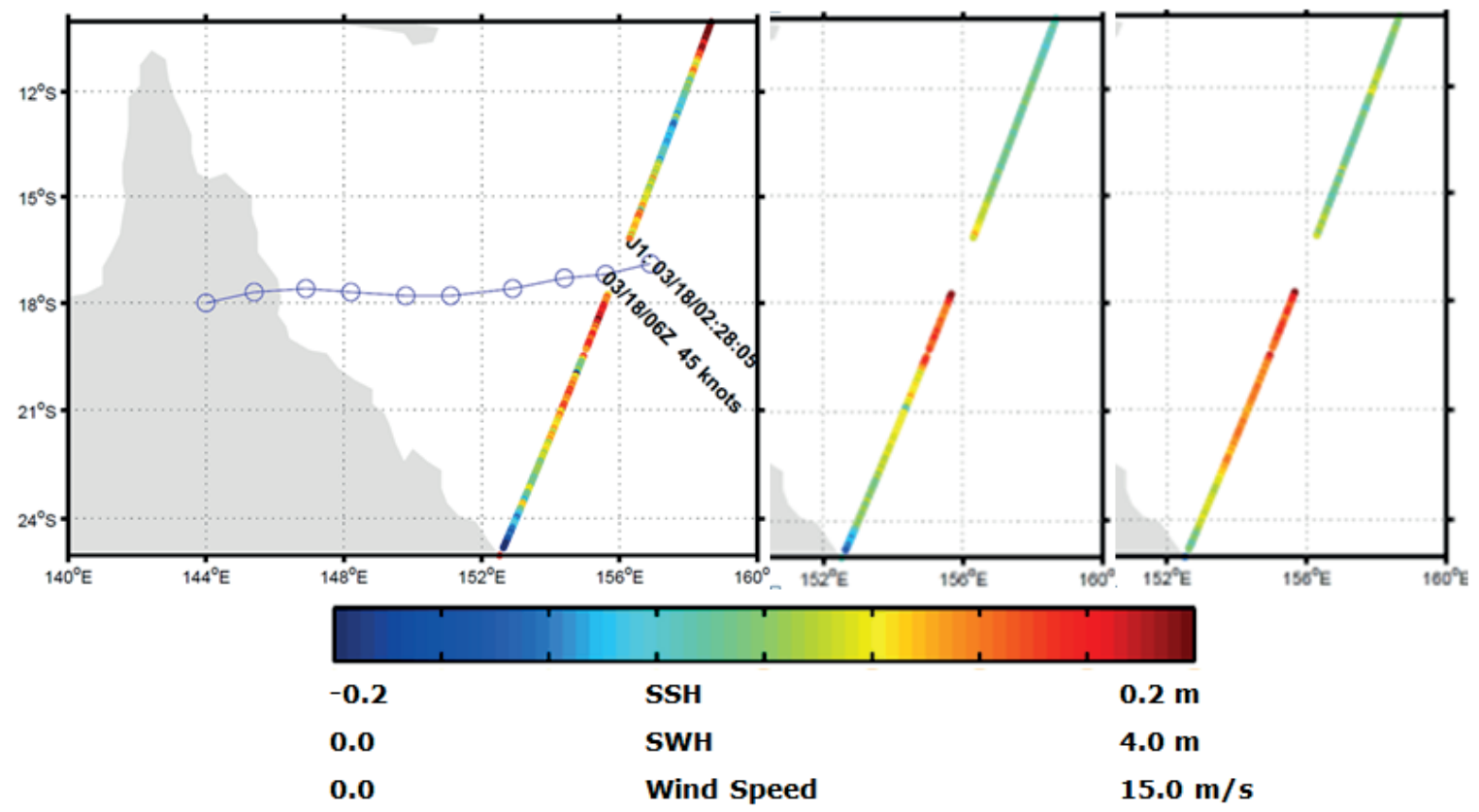

Fig. 5 Altimetric observations from RADS showing all tracks within 12 hours and $500 \mathrm{~km}$ of tropical cyclone Larry. In the case of Cyclone Larry only one track from Jason-1 could be used. Left figure shows sea surface height, central figure shows significant wave height and right figure shows the wind speed. The units are shown in the figure. The path of Cyclone Larry is highlighted in the left figure.



Fig. 6 Upper figure shows the locations of the six gauges used for predicting sea level at Townsville (near Cape Ferguson). The temporal correlation of the non-tidal signal between the tide gauge observations and satellite altimetry is colour coded in the figure. The lower figure shows the sea level observed at Cape Ferguson (blue) and predicted using a multi-regression model from the six other tide gauges only (green) and from including satellite altimetry (red). 
The lower part of Fig. 6 illustrates what happens when the tide gauge in Townsville is used for comparison of observed and predicted sea levels during the days of Cyclone Larry. The observed sea level at the Townsville is shown in blue and the predicted using a multi-regression model from the six tide gauges is shown in green. A multi-regression model taking the satellite altimetry into account is illustrated in red. The importance of including satellite altimetry is very clear and it increases the correlation between the observed and predicted sea level significantly.

\section{SUMMARY}

We have illustrated the importance of combining the coarse temporal sampling by the satellite altimeter in the deep ocean with the high temporal sampling at tide gauges in sparse locations. We have selected several representative high water events on the two continents based on tide gauge recordings and investigated the capability of the satellite altimeters to capture these in the sea surface height. On the European coast we find that when two or more satellites are available we capture more than $90 \%$ of the extreme sea level events defined as events with a surge height ranging more than two times the standard deviation of normal sea level range.

Cyclone Larry hit the Queensland state of Australian north of Townsville in March 2006. Examining the data delivered by the space agencies illustrated that most of the data within and close to the cyclone was rejected as they were flagged as invalid. However, a careful re-editing of the data enables us to reveal that the data could be used in a multi-regression model to forecast sea level at the tide gauge Townsville.

The importance of including satellite altimetry is very clear and it increases the correlation between the observed and predicted sea level significantly, which indicates that extreme sea level events can actually be forecast days in advance of the cyclone making landfall when carefully edited altimetry is used.

Acknowledgements The Space Agencies and the RADS altimeter archive are acknowledged for providing data for the investigation. The Inge Lehmann Foundation (Denmark) is acknowledged for supporting the work through a grant to O. Andersen.

\section{REFERENCES}

Andersen, O. B. (1999) Shallow water tides on the northwest European shelf from TOPEX/POSEIDON altimetry. J. Geophys. Res., 104, 7729-7741.

Andersen, O. B. \& Knudsen, P. (2009) The DNSC08 mean sea surface and mean dynamic topography models. J. Geophys. Res., doi:10.1029/2008JC005179

Andersen, O.B. \& Scharroo, R. (eds) (2010) Range and geophysical corrections in coastal regions. In: Coastal Altimetry (ed. by Vignudelli et al.), ISBN: 978-3-642-12795-3.

Cheng, Y.C., Andersen, O.B. \& Knudsen, P. (2012) Integrating non-tidal sea level data from altimetry and tide gauges for coastal sea level prediction. Advances in Space Research 50(8), 1099-1106.

Deng, X., et al. (2012) Integrated mapping of coastal sea level using altimetry and tide gauges for monitoring extreme sea levels. Proceedings of 20 years of Progress in Radar Altimetry, Venice, Italy, 24-29 September 2012.

Flather, R.A. (2000) Existing operational oceanography. Coastal Engineering, 41, 13-40.

Gill, A.E. (1982) Atmosphere-Ocean Dynamics. Academic Press, San Diego, California, USA. 662 pp.

Gönnert G., et al. (2001) Global Storm Surges. Die Küste - 63, ISBN 3-8042-1054-6, 623 pp.

Heaps N. S (1967) Storm surges. Oceanography and Marine Biology 5, 11-47.

Heaps, N. S. (1983) Storm surges, 1967-1982. Geophys. J. R. Soc. 74, 331-376.

Høyer, J.L. \& Andersen, O.B. (2002). Improved description of sea level in the North Sea. J. Geophys. Res. 108, C5 10.1029.

Shay, L K., Gronland, G.J. \& Black, P.G. (2000) Effects of a warm oceanic feature on Hurricane Opal. Mon. Weath. Rev. 128, 1366-1383.

Von Storch, H. \& Woth, K. (2008) Storm surges, perspectives and options. Sustainability Science 3, 33-44, doi 10.1007/ s11625-008-0044-2 